\section{A NEW ANTIBIOTIC LIBRAMYCIN A}

\section{Sir :}

A new antibiotic libramycin A has been isolated from the culture filtrate of a Streptomyces sp. No. 72-192 which was isolated from a soil sample collected at Sendai-shi, Miyagi Prefecture, Japan. Libramycin A, $\mathrm{C}_{11} \mathrm{H}_{20} \mathrm{~N}_{2} \mathrm{O}_{3}$, is a fat-soluble, weakly acidic substance, effective against some bacteria and fungi, especially against Mycobacterium phlei and Xanthomonas oryzae.

The composition of the culture medium used to produce libramycin A was $2 \%$ glucose, $1 \%$ starch, $2.5 \%$ soybean meal, $0.4 \%$ dry yeast, $0.1 \%$ beef extract, $0.2 \%$ sodium chloride and $0.005 \%$ dipotassium phosphate. The fermentation was carried out in a 600-liter tank for 96 hours at $27^{\circ} \mathrm{C}$. The active substance was adsorbed on active carbon $(1 \% \mathrm{w} / \mathrm{v})$ from the culture filtrate (400 liters) at pH 6 and eluted with $70 \%$ aqueous acetone. The active eluate was concentrated, acidified to $\mathrm{pH} 2$, and extracted with $n$-butanol. The antibiotic was re-extracted into water adjusted to $\mathrm{pH} 9$ with sodium hydroxide. The aqueous phase was neutralized to $\mathrm{pH} 6$ and the antibiotic in it was adsorbed on an active carbon column. The column was washed with water, and the antibiotic was eluted with $70 \%$ aqueous acetone. The active eluate was concentrated and applied to a Sephadex G-10 column. The column was developed with distilled water and the active fractions were combined and concentrated in vacuo to yield $1.2 \mathrm{~g}$ of crude

Fig. 1. Ultraviolet spectrum of libramycin A.

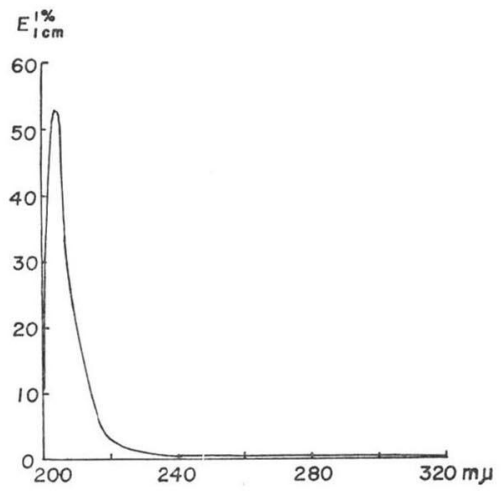

Fig. 2. Infrared spectrum of libramycin $\mathrm{A}(\mathrm{KBr})$.

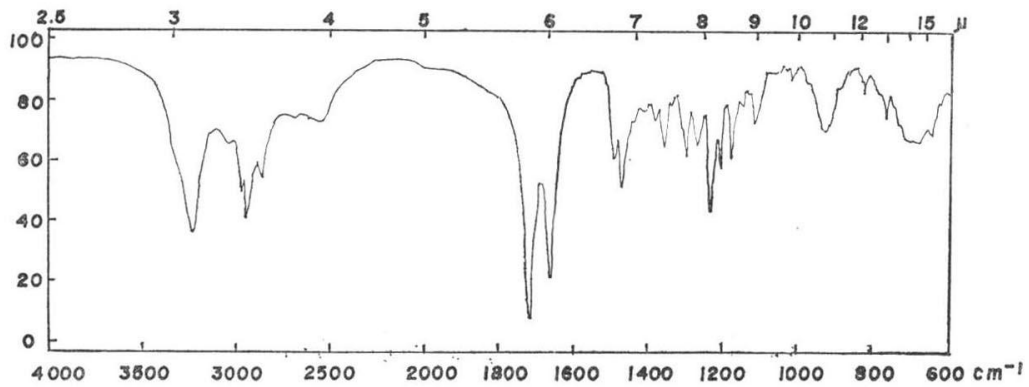

Fig. 3. NMR spectrum of libramycin $\mathrm{A}\left(100 \mathrm{MHz} \mathrm{C}_{5} \mathrm{D}_{5} \mathrm{~N}\right)$.

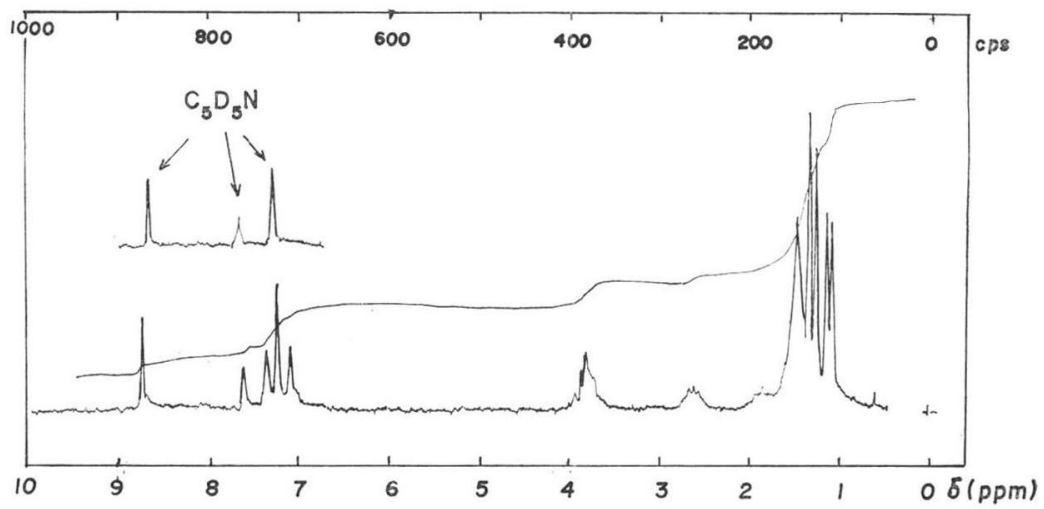


crystals. Recrystallization from hot water gave $0.98 \mathrm{~g}$ of libramycin A as colorless needles, m.p. $161 \sim 162^{\circ} \mathrm{C}$. It is an acidic substance with a pKá of 6.60 , and is optically active, $[\alpha]_{\mathrm{D}}^{25}-6.3^{\circ}(c 1$, methanol). It is easily soluble in methanol, ethanol, pyridine and alkali, soluble in acetone, ethyl acetate, chloroform and water, slightly soluble in ether and benzene, and insoluble in $n$-hexane.

Elementary analysis gave:

Calcd. for $\mathrm{C}_{11} \mathrm{H}_{20} \mathrm{~N}_{2} \mathrm{O}_{3}$ (M.W. 228):

$\mathrm{C} 57.89, \mathrm{H} 8.77, \mathrm{~N} 12.28, \mathrm{O} 21.05$

Found: $\quad$ C 57.75, H8.55, N 12.31, O 21.75

The molecular ion was observed at $m / e$ 228.14266 (calculated $m / e \quad 228.14737$ for $\mathrm{C}_{11} \mathrm{H}_{20} \mathrm{~N}_{2} \mathrm{O}_{3}$ ) by high resolution mass spectrometry, thus establishing the molecular formula. Libramycin A gives positive color reactions with anisaldehyde, $\mathrm{KMnO}_{4}$, ferric chloride, DRAGendorfF, MolisCH and EHRLICH reagents; negative reactions with ninhydrin, FeHLING, Sakaguchi, Biuret, Tollens and anthrone reagents. The ultraviolet absorption spectrum, Fig. 1, shows end absorption at $204 \mathrm{~nm}\left(E_{1 \mathrm{~cm}}^{1 \%} 53\right)$. The infrared spectrum is shown in Fig. 2. A $100 \mathrm{MHz}$ NMR spectrum of libramycin A dissolved in $\mathrm{C}_{5} \mathrm{D}_{5} \mathrm{~N}$ with TMS as an internal standard is shown in Fig. 3. Two signals, at $\delta 7.09$ and $\delta 7.36$, disappeared on the addition of a few drops of $\mathrm{D}_{2} \mathrm{O}$.

$\mathrm{R}_{f}$ values by paper chromatography were as follows: 0.80 (n-butanol saturated with water), 0.97 ( $3 \%$ ammonium chloride), 0.90 (75\% phenol), 0.96 (50\% acetone), 0.83 (n-butanolmethanol-water, $4: 1: 2$ ), and 0.66 (benzenemethanol, $4: 1$ ). Thin-layer chromatography with silica gel (Kieselgel-G, Merck) gave $\mathrm{R}_{f}$ values: 0.53 ( $n$-butanol saturated with water), 0.56 ( $n$-butanol-methanol-water, $4: 1: 2), 0.88$ (propanol - pyridine - acetic acid - water, 15:10: $3: 10), 0.87$ ( $n$-butanol-acetic acid-water, 3 : $1: 1$ ) and 0.32 (methanol-ethyl acetate, 15: $100)$.

The antimicrobial spectrum of libramycin A by the agar dilution method is shown in Table 1. The intraperitoneal injection of $400 \mathrm{mg} / \mathrm{kg}$ in mice did not elicit any toxic response. Two known antibiotics having $\mathrm{N}_{2} \mathrm{O}_{3}$ in their molecular formulae, nocardamin ${ }^{1,2)}$ and elaiomycin ${ }^{3)}$,
Table 1. Antimicrobial spectrum of libramycin A

\begin{tabular}{l|r}
\hline \multicolumn{1}{c|}{ Microorganisms } & M.I.C.(mcg/ml) \\
\cline { 2 - 2 } Staphylococcus aureus FDA 209P & $>100$ \\
Pseudomonas aeruginosa IFO 3445 & 20 \\
Mycobacterium phlei LEHMAN et & 1 \\
NeUMANN & \\
Mycobacterium smegmatis ATCC & 2 \\
607 & $>100$ \\
Escherichia coli NIHJ & $>100$ \\
Klebsiella dysenteriae & 2 \\
Xanthomonas oryzae ATCC 10031 & $>100$ \\
Trichophyton mentagrophytes & $>100$ \\
Trichophyton rubrum & $>100$ \\
Cryptococcus neoformans & $>100$ \\
Candida albicans Tokyo Univ. & $>100$ \\
Candida albicans 57 & 2 \\
Colletotrichum lagenarium & $>100$ \\
Aspergillus fumigatus & $>100$ \\
Alternaria kikuchiana & $>100$ \\
Fusarium oxysporum & $>100$ \\
Pyricularia oryzae cavara & \\
\hline
\end{tabular}

are differentiated from libramycin $\mathrm{A}$ on the basis of their physico-chemical properties.

These physico-chemical and biological properties indicate that libramycin $\mathrm{A}$ is a new antibiotic.

TAteo Yahagi Hideo Sugawara MASAKAzU URAMOTO SABURo SUZUKI

Antibiotic Laboratory The Institute of Physical and Chemical Research Wako-shi, Saitama 351, Japan

(Received August 31, 1973)

References

1) Stoll, A.; J. Renz \& A. Brack: Beiträge zur Konstitutionsaufklärung des Nocardamins. Helv. Chim. Acta 34: 862 873, 1951

2) Brown, R.E.C.; G. Büchi, W. KellerSchierlein, V. Prelog \& J. Renz: Über die Konstitution des Nocardamins. Helv. Chim. Acta 43: 1868 1871, 1960

3) Haskell, T.H.; A. Ryder \& Q.R. Bartz: Elaiomycin, a new tuberculostatic antibiotic. Isolation and chemical characterization. Antibiot. \& Chemoth. 4: 141 144, 1954 